\title{
Clearance of Amyloid Beta Plaques from Brain of Alzheimeric Rats by Lavandula angustifolia
}

\author{
Masoud Soheili ${ }^{1}$, Mostafa Rezaei Tavirani ${ }^{2}$, Mahmoud Salami ${ }^{3 *}$ \\ ${ }^{1}$ Student Research Committee, Faculty of Paramedical Sciences, Shaheed Beheshti University of Medical Sciences, Tehran, Iran; \\ ${ }^{2}$ Proteomics Research Center, Faculty of Paramedical Sciences, Shaheed Beheshti University of Medical Sciences, Tehran, Iran; \\ ${ }^{3}$ Physiology Research Center, Kashan University of Medical Sciences, Kashan, Iran.

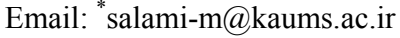

Received September $19^{\text {th }}, 2012$; revised October $19^{\text {th }}, 2012$; accepted November $22^{\text {nd }}, 2012$

\begin{abstract}
An important marker in neurodegenerative Alzheimer's disease (AD) is abnormal production of amyloid beta (A $\beta)$ peptide leading to formation of plaques in the brain. Through decreasing $\mathrm{A} \beta$ aggregates, anti-inflammatory agents, phagocytosis, and proteolytic enzymes are known to decline risk of $\mathrm{A} \beta$ plaque formation. In the previous study we showed that aqueous extract of Lavandula angustifolia (lavender), with known anti-inflammatory effects, improves memory deficits in animal model of Alzheimer. Here, we assess if lavender play a role in clearance of $A \beta$ plaques in the hippocampus. The Alzheimeric animals were created with intracerebroventricular injection of A $\beta$ 1-42. To confirm formation of $\mathrm{A} \beta$ plaques, brain sections were stained by Congo red method. Twenty days post-injection they were administered with different doses $(50,100$ and $200 \mathrm{mg} / \mathrm{kg})$ of the aqueous extract of lavender for duration of 20 days. Our results demonstrated that $50 \mathrm{mg} / \mathrm{kg}$ of lavender not effectively influenced the $\mathrm{A} \beta$ plaques. On the other hand, the herbal medicine at the doses of 100 and $200 \mathrm{mg} / \mathrm{kg}$ markedly decreased the extent of $\mathrm{A} \beta$ aggregates. We concluded that the lavender extract dose dependently underlies elimination of $\mathrm{A} \beta$ plaques. The exact mechanism by which the herbal medicine removes the $\mathrm{A} \beta$ aggregates needs to be elucidated.
\end{abstract}

Keywords: Alzheimer; Amyloid Beta; Lavandula angustifolia

\section{Introduction}

Alzheimer's disease (AD) is a progressive dementia disorder in elderly population. AD has a multifactorial pathology including accumulation of Amyloid $\beta$-peptide $(\mathrm{A} \beta)$, neuroinflammation and oxidative damage in the brain $[1,2]$. The $\mathrm{A} \beta$ derive from proteolytic cleavage of amyloid precursor protein by secretases family. Accumulation of aggregated $\mathrm{A} \beta$ is a major cause of cognitive disfunction in $\mathrm{AD}[3,4]$. The hippocampus and neocortex are the main targets for $\mathrm{A} \beta$ aggregates [5]. Many studies showed that i.c.v. injection of $\mathrm{A} \beta$ cause memory deficit in animals $[6,7]$.

Clearance of $\mathrm{A} \beta$ is a therapeutic method for delaying $\mathrm{AD}$ progression. One of the mechanisms in removing $\mathrm{A} \beta$ is mediated by liver and low-density lipoprotein receptorrelated protein (LRP-1) $[8,9]$. LRP-1 is a receptor for uptaking $\mathrm{A} \beta$ through hepatic [10]. Another mechanism that provokes clearance of $A \beta$ is accumulation of microglia. Microglia through expression of some classes of receptors like class A scavenger receptor and CD36 delay $\mathrm{AD}$ progression [11,12]. Also phagocytosis of $\mathrm{A} \beta$

${ }^{*}$ Corresponding author. plaques by microglia can restrict its accumulation in the brain [13]. Microglia also secrete proteolytic enzymes that degrade $\mathrm{A} \beta$, such as insulin-degrading enzyme, neprilysin, matrix metalloproteinase 9, and plasminogen, further suggesting a neuroprotective role for these cells in $\mathrm{AD}[14,15]$. However, persistent $\mathrm{A} \beta$ accumulation despite increasing microglial numbers suggests that the ability of microglia to clear $\mathrm{A} \beta$ may decrease with age and progression of AD pathology [13].

Experiments tracing the catabolism of radiolabeled $\mathrm{A} \beta$ in brain and by reverse genetics studies confirm that neprilysin is a rate-limiting peptidase participating in $\mathrm{A} \beta$ catabolism [16,17]. Neprilysin is particularly low in regions vulnerable to senile plaque development, such as hippocampus and midtemporal gyrus [18,19]. Recent reports demonstrated that immunotherapy is effective at preventing or removing $\mathrm{A} \beta$ deposits in the mouse models [20]. Single application of antiamyloid- $\beta$ antibodies to the surface of the brain in these mice led to clearance of existing senile plaques in the remarkably short time frame of 3 - 8 days $[20,21]$. An approach involving immunization of PDAPP mice with $\mathrm{A} \beta$ was shown to be effective at prevention of plaque deposition [22]. Brain- 
to-blood $\mathrm{A} \beta$ efflux transport across the blood-brain barrier and $\mathrm{A} \beta$ degradation by protease have been reported as cerebral A $\beta$ clearance mechanisms [23,24].

Evidence indicates that long term treatment with some nonsteroidal anti-inflammatory drugs (NSAIDs) reduce the risk for $\mathrm{AD}$, delay its onset, and slow the progression of the disease [25].

Lavender family is generally known for their multiple pharmacological effects such as anticonvulsant, sedative, antispasmodic, analgesic, antioxidant and local anesthetic activity [26]. Lavandula angustifolia (lavender), known as "Ostokhoddus" in Iran, is a strongly aromatic sub-shrub at the Mediterranean region. It grows to approximately $0.9 \mathrm{~m}$ high with leaves evergreen. Fresh flower tops of lavender are used for extract preparation $[27,28]$. The main compositions of lavender are linalool and linalyle acetate [29,30]. Additionally, lavender extracts inhibits glutamate-induced neurotoxicity and promotes anti-AchE activity enhancing the level of Ach in brain [31,32]. It is reported that lavender is an effective medical plant in treating inflammation, depression, stress and headache $[28,33]$. Lavender also is a strengthens of nervous system [34]. Aromatherapy effect of lavender in alleviation agitated behaviors is an aspect of treatment in patient with dementia [29]. These features can be important to treat dementia disorder such as AD. In our previous work we demonstrated that aqueous extract of lavender considerably influences the cognitive function of an Alzheimeric model of rats [27]. The present study aimed to evaluate if the positive effect of lavender treatment underlie clearance of beta amyloid plaques.

\section{Materials and Methods}

\subsection{Animals}

Experiments were conducted on adult male Wistar rats weighing 220 - 280 gr. The subjects were housed on a 12 $\mathrm{hr}$ light/dark schedule with lights on at 06:00 h and had food and water ad libitum. They were kept under a constant temperature $\left(21^{\circ} \mathrm{C} \pm 2{ }^{\circ} \mathrm{C}\right)$ and a humidity of $55 \% \pm$ $5 \%$.

Five groups of rats ( $n=9$ in each group) were introduced to behavioral experiments (for a spatial memory task) prior to histological assessments [27]. The animals were divided into control (CON) and Alzheimer disease (AD) groups. The AD group was further subdivided into 4 subgroups (AD, AE50, AE100, AE200; see below for more explanation). The animals were used in accordance with the guidelines of the Deputy of Research of the Kashan University of Medical Sciences.

\subsection{Animal Model of Alzheimer}

Rats were anesthetized with intraperitoneal injection of ketamine $(70 \mathrm{mg} / \mathrm{kg})$ and xylosine $(10 \mathrm{mg} / \mathrm{kg})$ and fixed on a stereotaxic instrument. The injection site was determined according to the Stereotaxic atlas [35]. A $4 \mathrm{~mm}$ stainless steel needle was implanted to the lateral ventricles $(\mathrm{AP}=$ Bregma, $\mathrm{LR}=1.5 \mathrm{~mm}, \mathrm{D}=4 \mathrm{~mm})$ as the cannulaes for the injection of $\mathrm{A} \beta$ 1-42. Injections were done using a 5 - $\mu$ l Hamilton syringe.

Animal model of AD was created by intracerebroventricularly injection of $10 \mu \mathrm{g} / 2 \mu \mathrm{l}$ aggregated $\mathrm{A} \beta 1-42$ peptide (Sigma Aldrich, St. Louis, MO, USA). The stock solution of $\mathrm{A} \beta 1-42(1 \mathrm{mg} / 200 \mathrm{ml})$ was prepared in distilled water. The solution was incubated at $37^{\circ} \mathrm{C}$ for 1 week before use. The CON rats received a same volume of $0.9 \% \mathrm{NaCl}$ injection. The injection site was confirmed by co-application of trypan blue.

\subsection{Preparation of Lavender Extract}

For extraction, $250 \mathrm{~g}$ dried flowers of Lavandula angustifolia (herbarium of Shaheed Beheshti University of Medical Sciences, Tehran, Iran) was mixed with $1000 \mathrm{ml}$ of boiled water. After stirring $4 \mathrm{hr}$ in a fully packed container, the mixture filtered and concentrated by vaporizing. The plant specimen was identified by Pharmaceutics Faculty of the University, where voucher specimens (1092) were kept.

\subsection{Extract Administration}

The concentrated aqueous extract of lavender was suspended in distilled water. The three groups of Alzheimeric rats were intraperitoneally received the aqueous extract of lavender with doses of 50,100 or $200 \mathrm{mg} / \mathrm{kg}$ (named AE50, AE100 and AE200 subgroups, respecttively). The $\mathrm{CON}$ and $\mathrm{AD}$ animals received distilled water. All the animals were injected at a volume of 0.4 $\mathrm{ml} / \mathrm{kg}$ body weight. The treatments were began 20 days after i.c.v. injections and continued once per day for 20 consecutive days.

\subsection{Histological Observations}

Twenty days after injection of the vehicle or $\mathrm{A} \beta$ the animals were killed and their brain was removed for histological evaluations. The $\mathrm{A} \beta$ treated animals were assessed for $\mathrm{A} \beta$ plaque formation. Samples for standard fixation were immersed in the appropriate fixative (formalin) for 48 to $72 \mathrm{~h}$ prior to processing. Overnight processing (including dehydration, clearing, and paraffin embedding) was performed using a Tissue Tek VIP5 automated processor (Sakura Finetek, Torrance, CA).

\subsection{Staining}

Sections were stained by Congo red method as reported previously [36]. Briefly, the rehydrated sections were incubated in alkaline saturated $\mathrm{NaCl}$ solution for 20 
minutes, and then immersed in alkaline Congo red solution for 30 minutes. After staining, the sections were dehydrated and fixed with Entellan. As shown in Figure 1(B), the staining confirmed the formation of $\mathrm{A} \beta$ plaque in the brain of $\mathrm{A} \beta$-treated animals.

\section{Results}

This study focused on histological modifications of hippocampus as a core region of brain involved in memory consolidation. The animals treated by $\mathrm{A} \beta$ peptide showed areas covered by $\mathrm{A} \beta$ plaques. The $\mathrm{A} \beta$ plaques were appeared as red islets scattered irregularly in the brain. Our criterion for the Anti-A $\beta$ effect of aqueous extract of lavender was the change in the extent of areas covered by $\mathrm{A} \beta$ plaques in the graphs taken from the rats receiving different doses of the herbal medicine.

\subsection{The CON and AD Animals}

Comparison of the sections from the $\mathrm{CON}$ and $\mathrm{A} \beta$ treated animals indicated an obvious difference between the two hippocampi. Whereas the CON hippocampus showed to be clean of the red areas (Figure 1(A)) the $\mathrm{A} \beta$ injected rats $(\mathrm{AD})$ developed $\mathrm{A} \beta$ red plaques, confirming that the $\mathrm{A} \beta$ treatment left the animals Alzheimeric (Figure 1(B)).

\subsection{The Effect of Aqueous Extract of Lavender on the $\mathbf{A} \boldsymbol{\beta}$ Plaques in the Hippocampus Area}

When formation of the $\mathrm{A} \beta$ plaques was confirmed the experiments were continued on the $\mathrm{A} \beta$ treated animals receiving different doses of the lavender extract to evaluate if the herbal medicine underlies the strength of the plaques. The sections prepared from $\mathrm{A} \beta$ treated AE50 rats resembled those from the AD animals. The plaques are comparatively visible in the hippocampus of the AE50 group, indicating that the dose $50 \mathrm{mg} / \mathrm{kg}$ of the aqueous extract not effectively influence removing the $\mathrm{A} \beta$ plaques (Figure 1(C)). Twenty days treating the AE100 group with $100 \mathrm{mg} / \mathrm{kg}$ of the plant extract considerably cleared the hippocampal sections from the $\mathrm{A} \beta$ plaques (Figure 1(D)). Concerning the red areas an obvious different is evident between the photomicrograph prepared from the AE100 animals compared to both the $\mathrm{AD}$ and $\mathrm{AE} 50$ groups. Increasing the concentration of the extract to $200 \mathrm{mg} / \mathrm{kg}$ further eliminated the $\mathrm{A} \beta$ plaques from the hippocampus of AE200 group (Figure 1(E)), indicating that the herbal extract dose dependently influence the $\mathrm{A} \beta$ clearance.

\section{Discussion}

Accumulation of neurotoxic $\mathrm{A} \beta$ peptide in the brain acts as the most important pathogenic marker contributing to neurodegeneration $[37,38]$. The levels of $\mathrm{A} \beta$ in the brain are controlled by its rates of production from the larger $\mathrm{A} \beta$-precursor protein and the rates of clearance $[14,39]$. The "CNS clearance hypothesis" is explained by entry of anti- $\mathrm{A} \beta$ antibodies into the brain where they bind $\mathrm{A} \beta$ and remove the $\mathrm{A} \beta$ plaques [40].

The present work demonstrated that aqueous extract of lavender effectively remove $\mathrm{A} \beta$ aggregates from the brain of an Alzheimeric model of rat. In our previous work we showed that the herbal medicine efficiently improved impaired spatial memory in the Alzheimeric animals [27]. Interestingly, both aspects of the extract action, including the $\mathrm{A} \beta$ clearance as well as the spatial memory improvement, occur in the same dose.

What are the mechanisms by which the lavender extract treats $\mathrm{A} \beta$ plaques? We administered the lavender extract intraperitoneally. Hence, the function of the extract could be appeared systematically. It is reported that a reduction in the plasma $\mathrm{A} \beta$ clearance by systemic organs is associated with an increased $\mathrm{A} \beta$ accumulation in the brain [13,23]. Although the animals were received $\mathrm{A} \beta$ intracerebroventricularly, however, via plasma clearance of $\mathrm{A} \beta$, the extract can help to decrease the $\mathrm{A} \beta$ level in brain. Since systemic clearance of $\mathrm{A} \beta$, especially by the liver, could determine the plasma levels of $\mathrm{A} \beta$ available for transport into the brain across the blood-brain barrier $[9,15]$ it can be concluded that the lavender may undergo the liver clearance of $\mathrm{A} \beta$. However, probable direct effect of the medicine on the $\mathrm{A} \beta$ plaques in the brain requires crossing the blood-brain barrier.

It is demonstrated that $\mathrm{A} \beta$ exhibit inflammatory effects in brain $[1,41]$. There are evidences for a direct role of NSAIDs on amyloid pathology $[4,42]$. Also, medium from microglia stimulated with $\mathrm{A} \beta$ but treated with NSAIDs displayed a protective effect in neurons [25]. Anti-inflammatory action of lavender is already proved [43]. Consequently, through clearance of $\mathrm{A} \beta$ plaque, the herbal extract may display its anti-inflammatory action.

Some endogenous agents are involved in clearance of $\mathrm{A} \beta$ from brain. $\mathrm{A} \beta$-degrading enzyme neprilysin is mainly detected presynaptically on or around axons in the hippocampal formation [44]. Neprilysin is suggested to regulate $\mathrm{A} \beta$ concentration around presynaptic sites so that a reduction of neprilysin activity may lead to local elevation of $\mathrm{A} \beta$ concentration in the extracellular space close to synapses, possibly affecting the local pathology during the course of $\mathrm{AD}$ development $[45,46]$. If some constituents of the lavender extract acts as an $\mathrm{A} \beta$ degrading itself or promote the function of some agents like neprilysin needs more study.

Our findings indicated that the lavender extract dose dependently influences the $\mathrm{A} \beta$ plaques elimination. Thus, higher concentrations of the extract probably further promote $\mathrm{A} \beta$ clearance. On the other hand, in the present work the extract treatment lasted for 20 days. Therefore, 

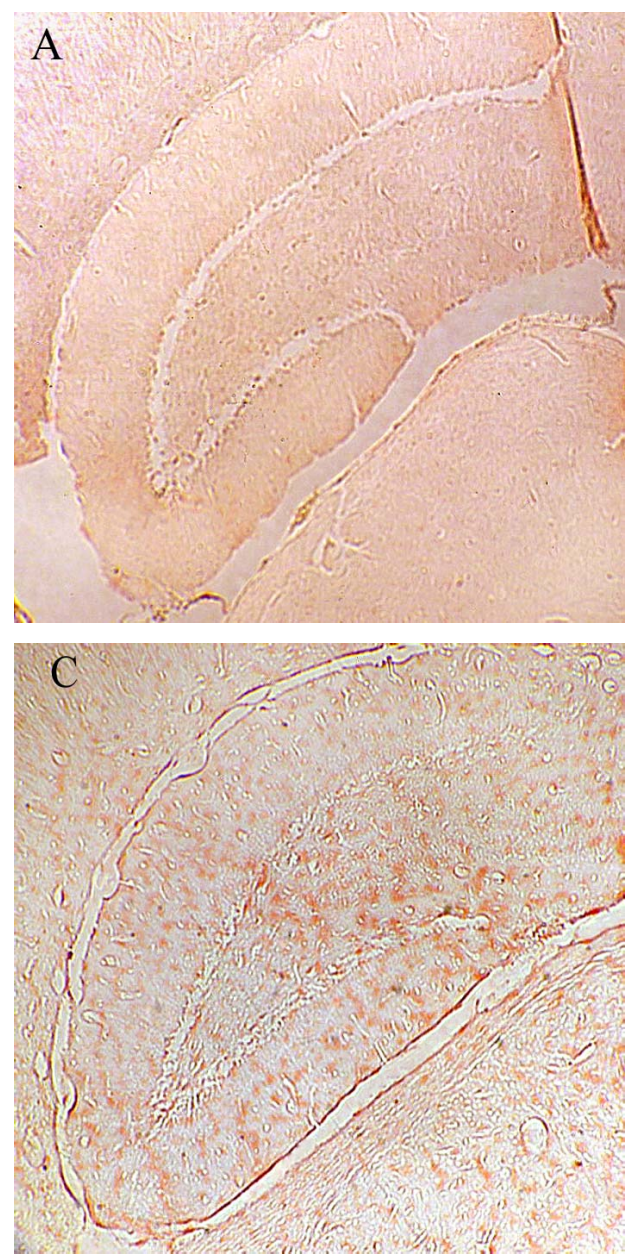
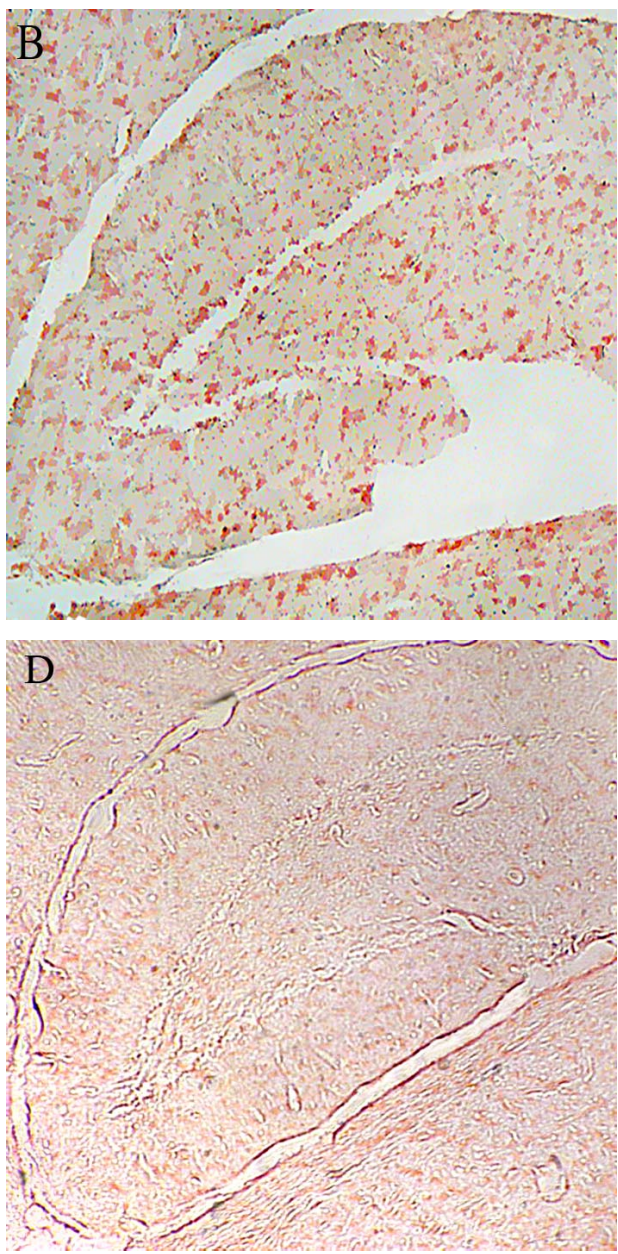

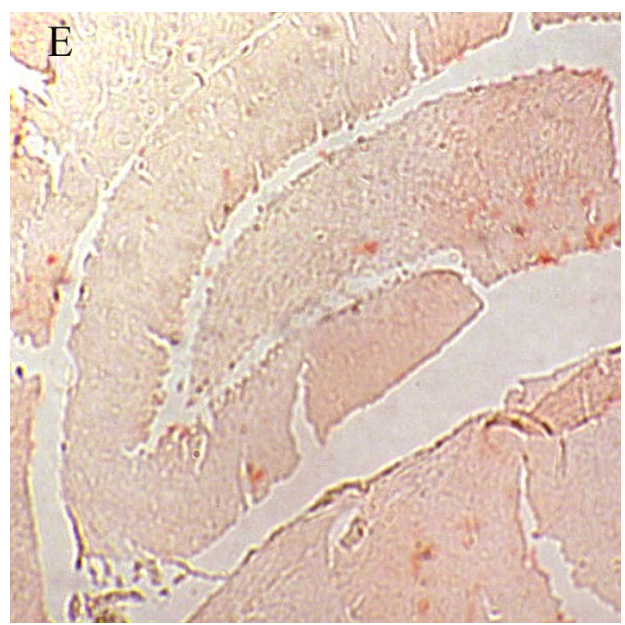

Figure 1. A: Control hippocampus, indicating no beta amyloid plaques in the brain $52 \times 39 \mathrm{~mm}(300 \times 300$ DPI); B: Hippocampus in the animals 20 days after intracerebroventricular injection of beta amyloid indicating an obvious different between the beta amyloid and vehicle treated hippocampi $52 \times 39 \mathrm{~mm}(300 \times 300 \mathrm{DPI})$; C: Hippocampus of the Alzheimeric rats after 20 days treatment with $50 \mathrm{mg} / \mathrm{kg}$ of the aqueous extract of lavender. The beta amyloid plaques are fairly observable so that the difference between this micrographs and the that of the Alzheimeric hippocampus are hardly distinguishable $52 \times 39 \mathrm{~mm}(300$ $\times 300$ DPI); D: Hippocampus of the Alzheimeric rats after 20 days treatment with $100 \mathrm{mg} / \mathrm{kg}$ of the aqueous extract of lavender. A clearance of beta amyloid plaques is evident when compared with the micrograph taken from the Alzheimeric hippocampus $52 \times 39 \mathrm{~mm}(300 \times 300 \mathrm{DPI})$; E: Hippocampus of the Alzheimeric rats after 20 days treatment with $200 \mathrm{mg} / \mathrm{kg}$ of the aqueous extract of lavender. As is observable this dose of the extract further disappeared the beta amyloid plaques from the brain $52 \times$ $39 \mathrm{~mm}(300 \times 300 \mathrm{DPI})$. 
it seems that a longer duration of the lower doses of lavender may be good enough to influence the $\mathrm{A} \beta$ plaques clearance. Whether or no pre-emptive application of the lavender extract helps to prevent $\mathrm{A} \beta$ plaques formation needs further investigation.

\section{Acknowledgements}

This work was financially supported by grant No. 8835 from Deputy of Research, Kashan University of Medical Sciences to Mahmoud Salami. We greatly thank Mr.s SA Talaei for his kind assistance. This study was planned and accomplished in Physiology Research Center, Kashan University of Medical Sciences.

\section{REFERENCES}

[1] H. W. Querfurth and F. M. LaFerla, "Alzheimer's Disease," The New England Journal of Medicine, Vol. 362, No. 4, 2010, pp. 329-344. doi:10.1056/NEJMra0909142

[2] J. Wang, et al., "Increased Oxidative Damage in Nuclear and Mitochondrial DNA in Alzheimer's Disease," Journal of Neurochemistry, Vol. 93, No. 4, 2005, pp. 953-962. doi:10.1111/j.1471-4159.2005.03053.x

[3] H. Hampel, et al., "Biological Markers of Amyloid $\beta$-Related Mechanisms in Alzheimer's Disease," Experimental Neurology, Vol. 223, No. 2, 2010, pp. 334-346. doi:10.1016/j.expneurol.2009.09.024

[4] I. Espuny-Camacho, et al., "Peroxisome Proliferator-Activated Receptor Gamma Enhances the Activity of an Insulin Degrading Enzyme-Like Metalloprotease for Amyloid-Beta Clearance," Journal of Alzheimer's Disease, Vol. 20, No. 4, 2010, pp. 1119-1132.

[5] G. Yamin, "NMDA Receptor-Dependent Signaling Pathways that Underlie Amyloid Beta-Protein Disruption of LTP in the Hippocampus," Journal of Neuroscience Research, Vol. 87, No. 8, 2009, pp. 1729-1736. doi:10.1002/jnr. 21998

[6] E. Mugantseva and I. Podolski, "Animal Model of Alzheimer's Disease: Characteristics of EEG and Memory," Vol. 4, No. 4, 2009, pp. 507-514.

[7] K. Yamada and T. Nabeshima, "Animal Models of Alzheimer's Disease and Evaluation of Anti-Dementia Drugs," Pharmacology \& Therapeutics, Vol. 88, No. 2, 2000, pp. 93-113. doi:10.1016/S0163-7258(00)00081-4

[8] B. Jeynes and J. Provias, "Evidence for Altered LRP/ RAGE Expression in Alzheimer Lesion Pathogenesis," Current Alzheimer Research, Vol. 5, No. 5, 2008, pp. 432437. doi:10.2174/156720508785908937

[9] K. K. Kandimalla, et al., "Pharmacokinetic Analysis of the Blood-Brain Barrier Transport of 125I-Amyloid Beta Protein 40 in Wild-Type and Alzheimer's Disease Transgenic Mice (APP,PS1) and Its Implications for Amyloid Plaque Formation," Journal of Pharmacology and Experimental Therapeutics, Vol. 313, No. 3, 2005, pp. 13701378. doi:10.1124/jpet.104.081901
[10] Y. Nishida, et al., "Depletion of Vitamin E Increases Amyloid Beta Accumulation by Decreasing Its Clearances from Brain and Blood in a Mouse Model of Alzheimer Disease," The Journal of Biological Chemistry, Vol. 284, No. 48, 2009, pp. 33400-33408. doi:10.1074/jbc.M109.054056

[11] B. Cameron and G. E. Landreth, "Inflammation, Microglia, and Alzheimer's Disease," Neurobiology of Disease, Vol. 37, No. 3, 2010, pp. 503-509. doi:10.1016/j.nbd.2009.10.006

[12] A. R. Simard, et al., "Bone Marrow-Derived Microglia Play a Critical Role in Restricting Senile Plaque Formation in Alzheimer's Disease," Neuron, Vol. 49, No. 4, 2006, pp. 489-502. doi:10.1016/j.neuron.2006.01.022

[13] S. E. Hickman, E. K. Allison and J. El Khoury, "Microglial Dysfunction and Defective Beta-Amyloid Clearance Pathways in Aging Alzheimer's Disease Mice," The Journal of Neuroscience, Vol. 28, No. 33, 2008, pp. 83548360. doi:10.1523/JNEUROSCI.0616-08.2008

[14] M. A. Leissring, et al., "Enhanced Proteolysis of BetaAmyloid in APP Transgenic Mice Prevents Plaque Formation, Secondary Pathology, and Premature Death," Neuron, Vol. 40, No. 6, 2003, pp. 1087-1093. doi:10.1016/S0896-6273(03)00787-6

[15] P. P. Yan, et al., "Matrix Metalloproteinase-9 Degrades Amyloid-Beta Fibrils in Vitro and Compact Plaques in Situ," The Journal of Biological Chemistry, Vol. 281, No. 34, 2006, pp. 24566-24574. doi:10.1074/jbc.M602440200

[16] N. Iwata, et al., "Region-Specific Reduction of a BetaDegrading Endopeptidase, Neprilysin, in Mouse Hippocampus upon Aging," The Journal of Neuroscience Research, Vol. 70, No. 3, 2002, pp. 493-500. doi:10.1002/jnr.10390

[17] N. Iwata, et al., "Metabolic Regulation of Brain Abeta by Neprilysin," Science, Vol. 292, No. 5521, 2001, pp. 15501552. doi:10.1126/science. 1059946

[18] K. Yasojima, et al., "Reduced Neprilysin in High Plaque Areas of Alzheimer Brain: A Possible Relationship to Deficient Degradation of Beta-Amyloid Peptide," Neuroscience Letters, Vol. 297, No. 2, 2001, pp. 97-100. doi:10.1016/S0304-3940(00)01675-X

[19] K. Yasojima, E. G. McGeer and P. P. L. McGeer, "Relationship between Beta Amyloid Peptide Generating Molecules and Neprilysin in Alzheimer Disease and Normal Brain," Brain Research, Vol. 919, No. 1, 2001, pp. 115121. doi:10.1016/S0006-8993(01)03008-6

[20] B. J. Bacskai, et al., "Non-Fc-Mediated Mechanisms are Involved in Clearance of Amyloid-Beta in Vivo by Immunotherapy," The Journal of Neuroscience, Vol. 22, No. 18, 2002, pp. 7873-7878.

[21] Y. Levites, et al., "Intracranial Adeno-Associated VirusMediated Delivery of Anti-Pan Amyloid Beta, Amyloid Beta40, and Amyloid Beta42 Single-Chain Variable Fragments Attenuates Plaque Pathology in Amyloid Precursor Protein Mice," The Journal of Neuroscience, Vol. 26, No. 46, 2006, pp. 11923-11928. doi:10.1523/JNEUROSCI.2795-06.2006

[22] D. Schenk, et al., "Immunization with Amyloid-Beta 
Attenuates Alzheimer-Disease-Like Pathology in the PDAPP Mouse," Nature, Vol. 400, No. 6740, 1999, pp. 173-177. doi: $10.1038 / 22124$

[23] M. Shibata, et al., "Clearance of Alzheimer's AmyloidSs(1-40) Peptide from Brain by LDL Receptor-Related Protein-1 at the Blood-Brain Barrier," Journal of Clinical Investigation, Vol. 106, No. 12, 2000, pp. 1489-1499. doi:10.1172/JCI10498

[24] D. J. Selkoe, "Clearing the Brain's Amyloid Cobwebs," Neuron, Vol. 32, No. 2, 2001, pp. 177-180. doi:10.1016/S0896-6273(01)00475-5

[25] B. A. in't Veld, et al., "Nonsteroidal Antiinflammatory Drugs and the Risk of Alzheimer's Disease," The New England Journal of Medicine, Vol. 345, No. 21, 2001, pp. 1515-1521.

[26] M. E. Buyukokuroglu, et al., "The Effects of Aqueous Extract of Lavandula Angustifolia Flowers in GlutamateInduced Neurotoxicity of Cerebellar Granular Cell Culture of Rat Pups," Journal of Ethnopharmacology, Vol. 84, No. 1, 2003, pp. 91-94. doi:10.1016/S0378-8741(02)00286-6

[27] M. S. Kashani, et al., "Aqueous Extract of Lavender (Lavandula Angustifolia) Improves the Spatial Performance of a Rat Model of Alzheimer's Disease," Neuroscience Bulletin, Vol. 27, No. 2, 2011, pp. 99-106. doi:10.1007/s12264-011-1149-7

[28] H. M. Kim and S. H. Cho, "Lavender Oil Inhibits Immediate-Type Allergic Reaction in Mice and Rats," Journal of Pharmacy and Pharmacology, Vol. 51, No. 2, 1999, pp. 221-226. doi:10.1211/0022357991772178

[29] P. P. W. Lin, et al., "Efficacy of Aromatherapy (Lavandula Angustifolia) as an Intervention for Agitated Behaviours in Chinese Older Persons with Dementia: A CrossOver Randomized Trial," International Journal of Geriatric Psychiatry, Vol. 22, No. 5, 2007, pp. 405-410. doi: $10.1002 /$ gps. 1688

[30] M. Lis-Balchin and S. Hart, "Studies on the Mode of Action of the Essential Oil of Lavender (Lavandula Angustifolia PP. Miller)," Phytotherapy Research, Vol. 13, No. 6,1999 , pp. 540-542. doi:10.1002/(SICI)1099-1573(199909)13:6<540::AID-PT R523>3.0.CO;2-I

[31] M. Bourin, N. Ripoll and E. Dailly, "Nicotinic receptors and Alzheimer's disease," Current Medical Research and Opinion, Vol. 19, No. 3, 2003, pp. 169-177. doi:10.1185/030079903125001631

[32] A. Adsersen, et al., "Screening of Plants Used in Danish Folk Medicine to Treat Memory Dysfunction for Acetylcholinesterase Inhibitory Activity," Journal of Ethnopharmacology, Vol. 104, No. 3, 2006, pp. 418-422. doi:10.1016/j.jep.2005.09.032

[33] T. Umezu, et al., "Anticonflict Effects of Lavender Oil and Identification of Its Active Constituents," Pharmacology Biochemistry and Behavior, Vol. 85, No. 4, 2006, pp. 713-721. doi:10.1016/j.pbb.2006.10.026

[34] Y. Kim, et al., "Effect of Lavender Oil on Motor Function and Dopamine Receptor Expression in the Olfactory Bulb of Mice," Journal of Ethnopharmacology, Vol. 125, No. 1, 2009, pp. 31-35. doi:10.1016/j.jep.2009.06.017

[35] A. Budantsev, et al., "[The Brain in Stereotaxic Coordinates (a Textbook for Colleges)]," Zhurnal Vysshě Nervnoĭ Deiatelnosti Imeni I P Pavlova, Vol. 43, No. 5, 1993, pp. 1045-1051.

[36] D. M. Wilcock, M. N. Gordon and D. Morgan, "Quantification of Cerebral Amyloid Angiopathy and Parenchymal Amyloid Plaques with Congo Red Histochemical Stain," Nature Protocols, Vol. 1, No. 3, 2006, pp. 15911595. doi: 10.1038/nprot.2006.277

[37] R. Deane, et al., “A Multimodal RAGE-Specific Inhibitor Reduces Amyloid Beta-Mediated Brain Disorder in a Mouse Model of Alzheimer Disease," Journal of Clinical Investigation, Vol. 122, No. 4, 2012, pp. 1377-1392. doi:10.1172/JCI58642

[38] A. Mathew, et al., “Alzheimer's Disease: Cholesterol a Menace?" Brain Research Bulletin, Vol. 86, No. 1-2, 2011, pp. 1-12. doi:10.1016/j.brainresbull.2011.06.006

[39] E. T. Parkin, et al., "Cellular Prion Protein Regulates BetaSecretase Cleavage of the Alzheimer's Amyloid Precursor Protein," PNAS, Vol. 104, No. 26, 2007, pp. 11062 11067. doi:10.1073/pnas.0609621104

[40] S. K. Gill, et al., "82-KDa Choline Acetyltransferase Is in Nuclei of Cholinergic Neurons in Human CNS and Altered in Aging and Alzheimer Disease," Neurobiology of Aging, Vol. 28, No. 7, 2007, pp. 1028-1040. doi:10.1016/j.neurobiolaging.2006.05.011

[41] E. E. Tuppo and H. R. Arias, "The Role of Inflammation in Alzheimer's Disease," The International Journal of Biochemistry \& Cell Biology, Vol. 37, No. 2, 2005, pp. 289-305. doi:10.1016/j.biocel.2004.07.009

[42] Q. Yan, et al., "Anti-Inflammatory Drug Therapy Alters Beta-Amyloid Processing and Deposition in an Animal Model of Alzheimer's Disease," The Journal of Neuroscience, Vol. 23, No. 20, 2003, pp. 7504-7509.

[43] V. Hajhashemi, A. Ghannadi and B. Sharif, "Anti-Inflammatory and Analgesic Properties of the Leaf Extracts and Essential Oil of Lavandula Angustifolia Mill," Journal of Ethnopharmacology, Vol. 89, No. 1, 2003, pp. 67-71. doi:10.1016/S0378-8741(03)00234-4

[44] S. Fukami, et al., "Abeta-Degrading Endopeptidase, Neprilysin, in Mouse Brain: Synaptic and Axonal Localization Inversely Correlating with Abeta Pathology," Neuroscience Research, Vol. 43, No. 1, 2002, pp. 39-56. doi:10.1016/S0168-0102(02)00015-9

[45] R. A. Marr, et al., "Neprilysin Gene Transfer Reduces Human Amyloid Pathology in Transgenic Mice," The Journal of Neuroscience, Vol. 23, No. 6, 2003, pp. 1992-1996.

[46] N. Iwata, et al., "Presynaptic Localization of Neprilysin Contributes to Efficient Clearance of Amyloid-Beta Peptide in Mouse Brain," The Journal of Neuroscience, Vol. 24, No. 4, 2004, pp. 991-998. doi:10.1523/JNEUROSCI.4792-03.2004 